\title{
Is obesity an eating disorder?
}

\author{
BY SUSAN A. JEBB AND ANDREW M. PRENTICE \\ MRC Dunn Clinical Nutrition Centre, Hills Road, Cambridge CB2 2DH
}

It is simplistic to imagine that the entire problem of obesity is, or is not, an eating disorder. One of the few consensus views in this field is that obesity is a multi-factorial entity, in which the aetiology and treatment are unlikely to follow a single unified line of reasoning. Yet it is probable that an understanding of the nature of eating disorders, and their relevance to subgroups of the obese population, may assist our understanding and treatment of this complex problem.

\section{HYPOMETABOLISM OR HYPERPHAGIA?}

For years many obese subjects have believed that they have a metabolic disorder, since they perceive that they eat no more than their lean counterparts but have a constant battle against their increasing body weight. Through numerous diet histories and food records this theory has gained credence since reported energy intakes in obese and lean individuals are very similar on an absolute basis and significantly lower in the obese when expressed in terms of body weight (e.g. Fig. 1). This finding can only be reconciled with the increased body weight of these subjects by assuming they have a low metabolic rate. The phrase 'It's my metabolism' has become a socially acceptable justification for obesity, which goes some way towards attracting the public sympathy usually reserved for those with a disease process and rarely given to obese subjects with what is often perceived to be a self-inflicted problem.

(a) Absolute energy intake

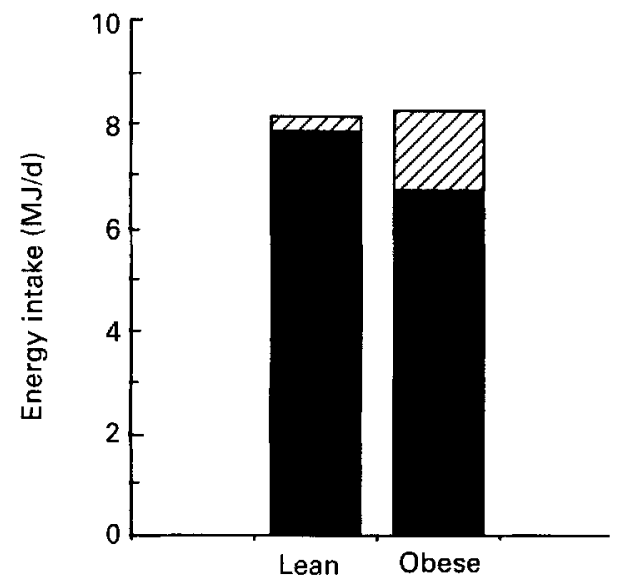

(b) Energy intake per kg

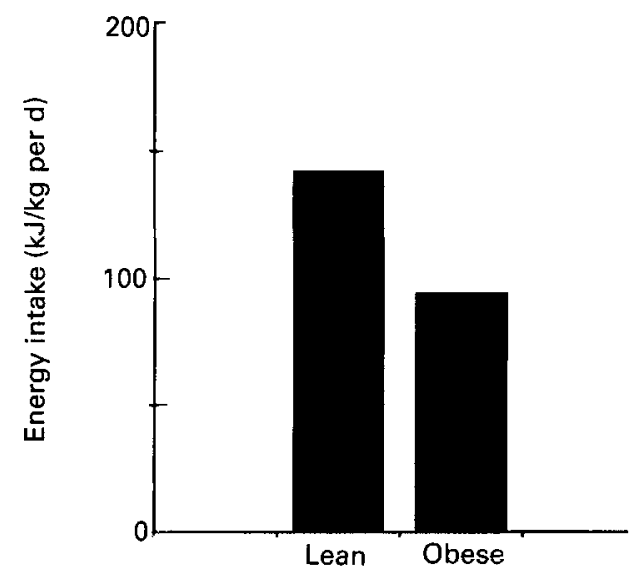

Fig. 1. Self-reported daily energy intake of lean and obese subjects. (a) Absolute energy intake, (b) intake per $\mathrm{kg}$ body weight. $(\mathscr{Z})$, Correction for the loss of body energy reserves during measurements of energy intake. (Data from Prentice et al. 1986) 
(a)

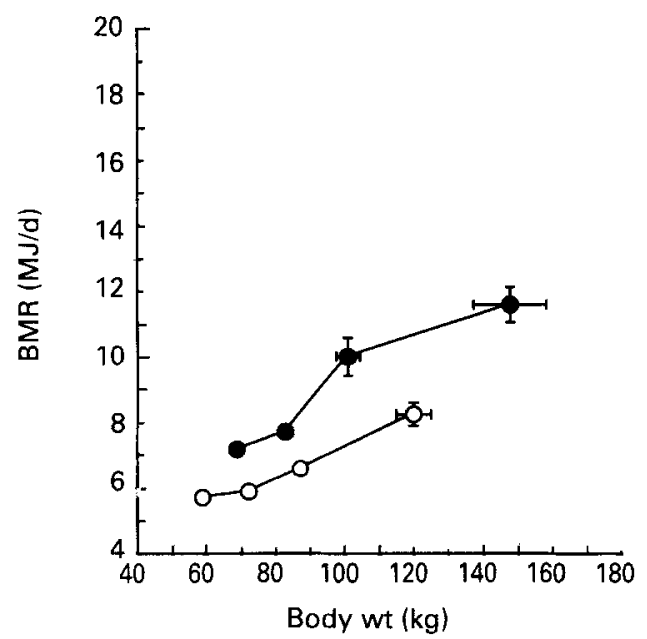

(b)

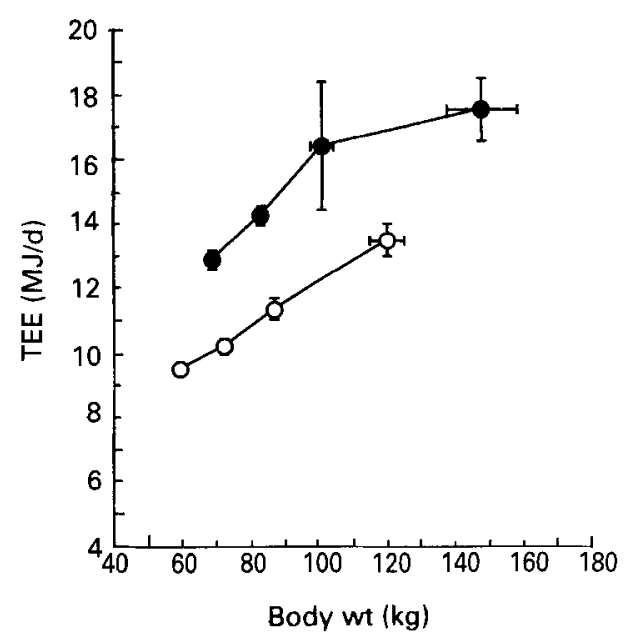

Fig. 2. Meta-analysis of energy expenditure in relation to body weight. (a) BMR, (b) total energy expenditure (TEE). Values are means with their standard errors represented by vertical bars, for 212 women $(O)$ and 107 men (@). (Redrawn from Prentice et al. 1995)

However, direct measurements of energy expenditure in obese subjects do not substantiate this claim. Within the confines of a whole-body calorimeter and on a fixed exercise protocol, obese subjects consistently expend more energy than their lean counterparts, at all times of day and in all activities (Prentice et al. 1989). This effect is apparent both in terms of the BMR and the energy cost of activity. However, if energy expenditure is expressed per unit body weight the energy expenditure of lean and obese subjects is remarkably similar.

These findings are confirmed by studies of free-living energy expenditure, whilst subjects are engaged in their usual daily activities (Prentice et al. 1986). Measurements made over $14 \mathrm{~d}$, using doubly-labelled water, demonstrate that obese subjects expend significantly more energy than their lean counterparts. Similar evidence is now accumulating from a number of studies world-wide and is confirmed by a recent meta-analysis of 319 measurements of total energy expenditure (TEE; Prentice et al. 1995). Fig. 2 shows that in both men and women BMR increases progressively as body weight increases. Furthermore the total energy costs (including activity and thermogenesis) are also increased in obese subjects. It is only in the grossly-obese men (BMI $>35 \mathrm{~kg} / \mathrm{m}^{2}$ ) that the rate of increase in TEE is not proportional to body weight. It is reasonable to assume that in subjects of this size physical limitations to the amount and type of activity which can be performed restrict energy expenditure.

These findings demonstrate that, contrary to popular opinion, TEE in obese subjects is increased compared with their lean counterparts, and not decreased, such that individuals with a BMI in excess of $30 \mathrm{~kg} / \mathrm{m}^{2}$ have an energy expenditure approximately $25 \%$ higher that those with a BMI less than $25 \mathrm{~kg} / \mathrm{m}^{2}$. This suggests also that in order to maintain energy balance obese individuals must be eating significantly more than their lean counterparts (Prentice et al. 1986; Schoeller, 1990). Food balance studies performed in metabolic wards confirm this to be the case (Lichtman et al. 1992). This is contrary to a 


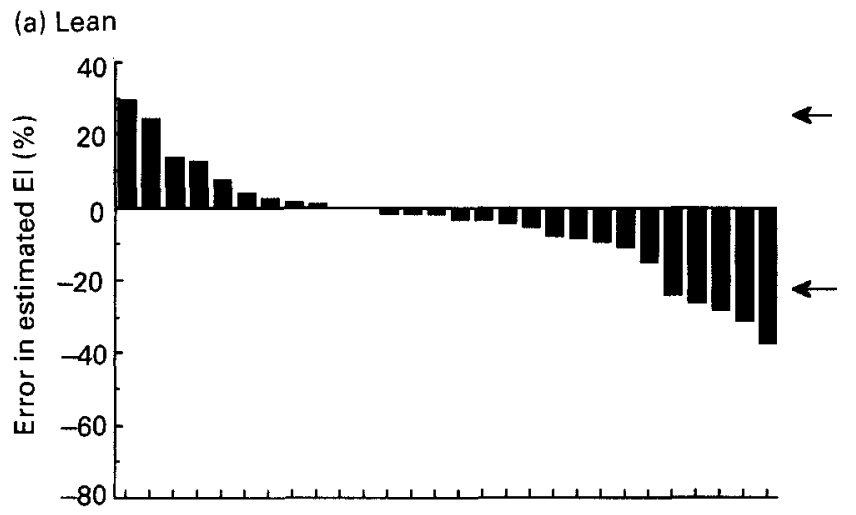

(b) Post-obese and obese

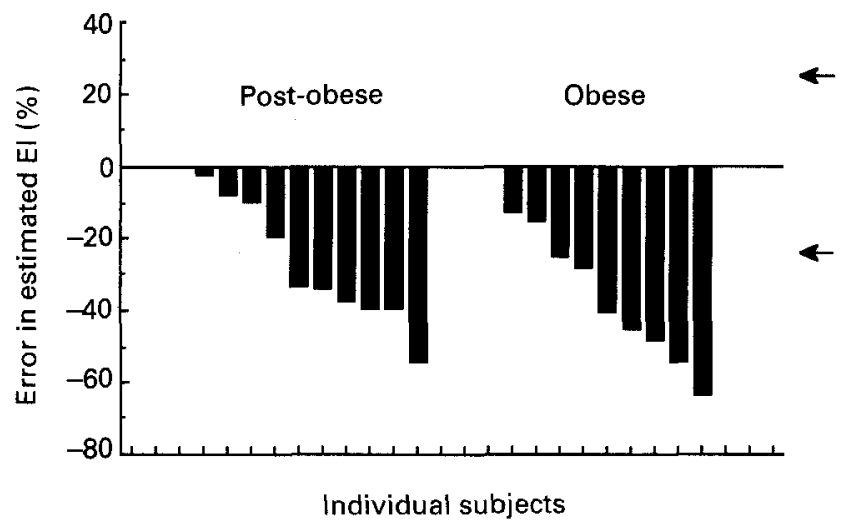

Fig. 3. Differences between self-reported energy intake and measured energy expenditure for (a) lean volunteers and (b) obese and post-obese volunteers. \&-, Limits of measurement precision. (Redrawn from Black et al. 1993)

plethora of dietary surveys of food intake, but it is clear that food intake records substantially under-report the habitual energy intake of obese subjects. This underreporting cannot be explained simply by subjects dieting during periods of food recording since this effect persists even after correction for losses of body energy stores.

Fig. 3 shows the magnitude of under-reporting. In the lean subjects, although there is substantial inter-individual variability, as would be expected from a limited period of recording, the mean energy balance is close to zero. There is no evidence of systematic bias. In contrast, energy-balance data in both obese and post-obese subjects (successful slimmers) show under-reporting of energy intake in each individual, producing a significant group bias of -36 and $-27 \%$ in obese and post-obese subjects respectively.

\section{OBESE BINGE-EATERS (OBE)}

Many health professionals recognize a subgroup of obese subjects in whom attempts at weight control are undermined by intermittent bouts of binge-eating, reminiscent of that 
Table 1. DSM-IV research criteria for binge-eating disorder (From American Psychiatric Association, 1994)

(A) Recurrent episodes of binge-eating. An episode of binge-eating is characterized by both the following:

1. eating, in a discrete period of time (e.g. within any $2 \mathrm{~h}$ period) an amount of food that is definitely larger than most people would eat in a similar period of time under similar circumstances

2. a sense of lack of control over eating during the episode

(B) The binge-eating episodes are associated with three (or more) of the following:

1. eating much more rapidly than normal

2. eating until feeling uncomfortably full

3. eating large amounts of food when not feeling physically hungry

4. eating alone because of being embarrassed by how much one is eating

5. feeling disgusted with oneself, depressed or very guilty after overeating

(C) Marked distress regarding binge-eating is present

(D) The binge-eating occurs, on average, at least $2 \mathrm{~d}$ per week for 6 months

seen in bulimia nervosa. Using the DSM-III criteria (American Psychiatric Association, 1994) for bulimia it has been estimated that $23 \%$ of obese subjects may exhibit such characteristics (Keefe et al. 1984). Recently, specific DSM-IV criteria (American Psychiatric Association, 1994) have been established for research in this field (Table 1) and a recent study has estimated that $30.1 \%$ of patients presenting for treatment can be defined as OBE, compared with less than $2 \%$ in a community sample (Spitzer et al. 1992).

Data from the eating disorder examination (EDE) suggest that the psychological profile of these patients is significantly different from that of control subjects, but has much in common with patients with bulimia nervosa (Fig. 4). Scores for overeating, shape concern, weight concern and eating concern are remarkably similar, although $\mathrm{OBE}$ tend to have much lower scores for dietary restraint. It has been suggested that OBE may represent a group who have tried and failed so often to lose weight that they have abandoned their dieting efforts and the associated dietary restraint. In comparison with other obese individuals, those classified as OBE report significantly less perceived control over eating, more fear of weight gain, more dissatisfaction with their weight, more preoccupation with their weight and with food (Wilson et al. 1993). In addition, OBE also have a significantly higher incidence of depression (Yanovski et al. 1992).

A limited number of studies have looked at the response to treatment with respect to the eating behaviour of the patients in an attempt to match patients to the most appropriate treatment plan. One such study (Marcus et al. 1988) showed similar weight loss in OBE compared with non-bingers within a conventional behavioural weight-loss programme. However, weight rebound was more rapid in the OBE, although at the 1-year follow-up the difference between groups was not significant. It was noticeable that throughout the study and follow-up period there was no significant change in eating behaviour as determined by scores in the EDE.

Alternatively it has been suggested that treatment of the eating disorder should be the first line of therapy. Reports of OBE patients treated with cognitive behavioural therapy have demonstrated significant improvements in eating behaviour and specific reductions 




Fig. 4. Eating disorder examination (EDE) scores for groups of obese binge-eaters $(\boldsymbol{O})$, normal-weight bulimia nervosa patients $(\triangle)$ and normal-weight restrained eaters $(\boldsymbol{\Delta})$. (Redrawn from Marcus et al. 1992)

in binge-eating (Telch et al. 1990; Smith et al. 1992). However, this has not in itself produced a reduction in body weight. This is perhaps not surprising since the therapy focuses on removing dietary restraint and inhibition regarding food choices and does not attempt to introduce the food intake control necessary for weight loss.

Interest is now centred on combining elements of both these treatments, but as yet there are no outcome data available. To what extent the two goals of weight loss and the reduction in inappropriate eating behaviours are synergistic or antagonistic has not been evaluated. It may be postulated that if the eating binges account for a large proportion of energy intake, curbing the occurrence of such episodes through improvements in eating behaviour and the reduction in inappropriate attitudes towards food will naturally reduce total energy intake, or that successful weight reduction will remove the drive to a fasting-feasting cycle and the aberrant eating behaviour. Alternatively, it is possible that the two forms of treatment are mutually exclusive, since dietary management teaches dietary restraint whilst behavioural therapy aims to minimize restrictive eating practices.

OBE are a single example of a group who appear to have a specific, clinically-definable eating disorder. The classification of OBE is largely based on eating behaviour, but it is conceivable that there are also other subgroups of obese patients with an eating disorder which is identifiable on a physical or organic basis. One example of such a potential group may be those with a genetically-determined characteristic. Traditionally a genetic predisposition to obesity has been considered in the context of differences in energy expenditure between individuals. However, following the recent sequencing of the ob/ob gene in genetically-obese mice it has been suggested that this gene codes for a satiety or 'stop eating' signal (Zhang et al. 1994). Defects of this type may be linked to an organic cause for the hyperphagia of obesity, not unlike that seen in the Prader-Willi syndrome. 
Clearly there is some credence to the proposition that obesity is an eating disorder. First there is little evidence of energy-sparing defects in the obese and the corollary of this is that energy intake must be increased. Second there is substantial under-reporting of energy intake which itself may be symptomatic of an underlying eating disorder. In addition, it appears that there may be subgroups of the obese population who may have a physical or psychologically-defined eating disorder.

\section{THE PUBLIC HEALTH PERSPECTIVE}

The first half of the present paper has considered obesity as a problem of individuals, but it is also one of the most significant public health problems in Europe today (Department of Health, 1992). In this context there are a number of other factors which may be of greater significance than eating disorders in determining the nature of the obesity problem.

In the last decade the prevalence of obesity in the UK has doubled, such that in 1991 $12 \%$ of men and $15 \%$ of women were classified as obese, with a BMI $>30 \mathrm{~kg} / \mathrm{m}^{2}$ (White et al. 1993). Within these overall numbers several trends are evident. The prevalence of obesity increases with advancing age in both men and women, with a fourfold rise in the prevalence of obesity from young adults to those aged 60-69 years in both men and women. Social class also exerts a powerful influence and there is a twofold greater prevalence of obesity in women in social classes IV $+V$ than I + II.

These secular trends suggest that at a population level obesity may be determined more by cultural and environmental and/or behavioural effects, rather than by organic eating disorders. Even the potential role of genetics is minimized by the significant changes in the prevalence of the problem occurring over such short periods of evolutionary time.

Nonetheless there is a popular belief that the plentiful supply of an increasing variety of foods is a contributory factor in the rising prevalence of obesity. However, national food intake data do not support this view. Indeed, quite the converse is true. Data from the National Food Survey (NFS) show a progressive decrease in energy intake since 1970 (Ministry of Agriculture, Fisheries and Food, 1940-1994). This effect is apparent even when adjusted for known omissions in the NFS data such as alcohol, confectionery and soft drinks. The NFS data are supported by numerous cross-sectional surveys of food intake. The net effect is that energy intakes appear to have declined by approximately $3 \mathrm{MJ} /$ person per d over the last 20 years (Prentice \& Jebb, 1995).

The increase in obesity, but decrease in energy intake, can only be reconciled by hypothesizing a marked decrease in energy expenditure. Since BMR will have increased slightly as a consequence of the rise in body weight the decrease in energy expenditure must have occurred in physical activity.

Unfortunately there have been few longitudinal studies on physical activity. However, cross-sectional data suggest that as a nation we are remarkably inactive. Less that $10 \%$ of women and $20 \%$ of men are now in active occupations, $80 \%$ of adults never walk continuously for 2 miles and the top five leisure pursuits listed by the General Household Survey are all sedentary: TV viewing, visiting or entertaining friends, listening to radio, records or tapes and reading (Office of Population Censuses and Surveys, 1992). Active pastimes come much lower on the list. The belief that television has become the major leisure industry in the UK is reinforced by TV viewing figures. The average number of 
(a) Energy intake

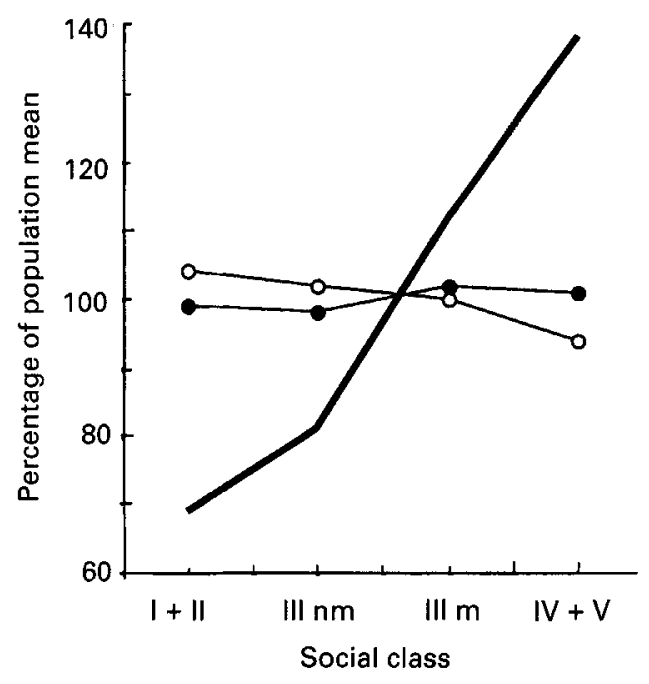

(b) Physical activity

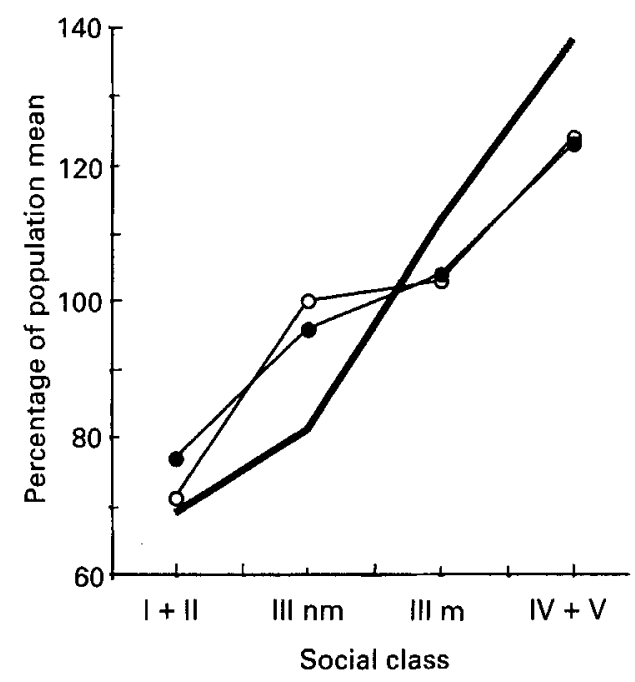

Fig. 5. Patterns of (a) energy intake and (b) physical activity in relation to social class trends in the prevalence of obesity. (a) (-), percentage of population classified as obese; $(\mathrm{O})$, energy intake $(\mathrm{MJ} / \mathrm{d}) ;(\bullet)$, energy intake (\% fat energy); (b) (-), percentage of population classified as obese; $(O)$, percentage inactive; $(\boldsymbol{\bullet})$, percentage viewing TV. (Data: diet (women only) from Gregory et al. (1990), prevalence of clinical obesity (women only) from Office of Population Censuses and Surveys (White et al. 1993), TV viewing and car ownership (both sexes) from Central Statistical Office (Office of Population Censuses and Surveys, 1992).)

hours spent watching TV per week has increased from 14 in 1961 to 26 in 1992 (Office of Population Censuses and Surveys, 1992). Videos and computer games have added to this effect in recent years.

These longitudinal trends in the patterns of energy intake and expenditure in relation to the trends in obesity are also observed cross-sectionally when investigating the social-class gradient in obesity (Fig. 5). Differences in total energy intake are small, although minor differences in fat intake have been implicated in the aetiology of obesity. However, there is a striking similarity in the prevalence of physical inactivity and obesity.

Thus, it seems more likely that physical inactivity is implicated in the rise in obesity rather than hyperphagia and increased energy intake.

\section{CONCLUSIONS}

The present paper has argued both for and against the possibility that obesity may be considered to be an eating disorder. In practice these two lines of evidence are not mutually exclusive. There is without doubt a shift in the population distribution towards increased body weights which is unlikely to be due to a national eating disorder, but is the end-result of numerous environmental and behavioural changes within the population.

However, this hypothesis does not preclude the suggestion that there are obese or overweight people at the top end of the population distribution of BMI, who have a clinically-definable eating disorder based on physical or psychological criteria, such as 
OBE. Identifying subgroups of the population in this way will be another piece in our understanding of the nature of this disorder and perhaps another step towards improving the management of this recalcitrant public health problem.

\section{REFERENCES}

American Psychiatric Association (1994). Diagnostic and Statistical Manual of the American Psychiatric Association, 3rd ed. Washington, DC: American Psychiatric Association.

Black, A. E., Prentice, A. M., Goldberg, G. R., Jebb, S. A., Bingham, S. A., Livingstone, M. B. E. \& Coward, W. A. (1993). Measurements of total energy expenditure provide insights into the validity of dietary measurements of energy intake. Journal of the American Dietetic Association 93, 572-579.

Department of Health (1992). The Health of the Nation. London: H.M. Stationery Office.

Gregory, J., Foster, K., Tyler, H. \& Wiseman, M. (1990). The Dietary and Nutritional Survey of British Adults. London: H.M. Stationery Office.

Keefe, P. H., Wyshogrod, D., Weinberger, E. \& Agras, W. S. (1984). Binge eating and outcome of behavioural treatment of obesity: A preliminary report. Behaviour Research and Therapy 22, 319-321.

Lichtman, S. W., Pisarska, K., Berman, E. R., Pestone, M., Dowling, H., Offenbacher, E., Weisel, H., Heshka, S., Matthews, D. E. \& Heymsfield, S. B. (1992). Discrepancy between self-reported and actual caloric intake and exercise in obese subjects. New England Journal of Medicine 327, 1893-1898.

Marcus, M. D., Smith, D., Santelli, R. \& Kaye, W. (1992). Characterisation of eating disordered behaviour in obese binge eaters. International Journal of Eating Disorders 12, 249-256.

Marcus, M. D., Wing, R. R. \& Hopkins, J. (1988). Obese binge eaters: Affect, cognitions and response to behavioural weight control. Journal of Consulting and Clinical Psychology 56, 433-439.

Ministry of Agriculture, Fisheries and Food (1940-1994). Household Food Consumption and Expenditure (Annual Reports). London: H.M. Stationery Office.

Office of Population Censuses and Surveys (1992). General Household Survey. London: H.M. Stationery Office.

Prentice, A. M., Black, A. E., Coward, W. A. \& Cole, T. J. (1995). Energy expenditure in overweight and obese adults in affluent societies: An analysis of 319 doubly-labelled water measurements. European Journal of Clinical Nutrition (In the Press).

Prentice, A. M., Black, A. E., Coward, W. A., Davies, H. L., Goldberg, G. R., Murgatroyd, P. R., Ashford, J., Sawyer, M. \& Whitehead, R. G. (1986). High levels of energy expenditure in obese women. British Medical Journal 292, 983-987.

Prentice, A. M., Black, A. E., Murgatroyd, P. R., Goldberg, G. R. \& Coward, W. A. (1989). Metabolism or appetite? Questions of energy balance with particular reference to obesity. Journal of Human Nutrition and Dietetics 2, 95-104.

Prentice, A. M. \& Jebb, S. A. (1995). Obesity in Britain: Gluttony or Sloth. British Medical Journal 311, 437-439.

Schoeller, D. A. (1990). How accurate is self-reported dietary energy intake? Nutrition Reviews 48, 373-379.

Smith, D. E., Marcus, M. D. \& Kaye, W. (1992). Cognitive-behavourial treatment of obese binge eaters. International Journal of Eating Disorders 12, 257-262.

Spitzer, R. C., Devlin, M., Walsh, B. J., Hasin, D., Wing, R. R., Marcus, M. D., Stunkard, A., Wadden, T., Yanovski, S., Agras, S., Mitchell, J. \& Nonas, C. (1992). Binge eating disorder: A multisite field trial of the diagnostic criteria. International Journal of Eating Disorders 11, 191-203.

Telch, C. F., Agras, W. S., Rossiter, E. M., Wilfley, D. \& Kenardy, J. (1990). Group cognitive-behavioural treatment for the non-purging bulimic: An initial evaluation. Journal of Consulting and Clinical Psychology $58,629-638$.

White, A., Nicolaas, G., Foster, K., Browne, F. \& Carey, S. (1993). Health Survey for England 1991. London: Office of Population Censuses and Surveys/H.M. Stationery Office.

Wilson, G. T., Nonas, C. A. \& Rosenblum, G. D. (1993). Assessment of binge eating in obese patients. International Journal of Eating Disorders 13, 25-34

Yanovski, S. Z., Leet, M., Janovsky, J. A., Flood, M., Gold, P. W., Kissileff, H. R. \& Walsh, B. T. (1992). Food selection and intake of obese women with binge-eating disorder. American Journal of Clinical Nutrition 56, 975-980.

Zhang, Y., Proenca, R., Maffei, J., Barone, M., Leopold, L. \& Friedman, J. M. (1994). Positional cloning of the mouse obese gene and its human homologue. Nature 372, 425-432. 